\title{
Oxymatrine attenuates lipopolysaccharide-induced acute lung injury by activating the epithelial sodium channel and suppressing the JNK signaling pathway
}

Bingji JIN ${ }^{1,2)}$ and Hong JIN ${ }^{1)}$

1) Department of Pathogen Biology, China Medical University, 77 Puhe Road, Shenyang, Liaoning 110013, P.R. China

${ }^{2)}$ Department of Cardiothoracic Surgery, The First Affiliated Hospital of Jinzhou Medical University, No. 2, Section 5, Renmin Street, Jinzhou, Liaoning 121001, P.R. China

\begin{abstract}
The epithelial sodium channel $(\mathrm{ENaC})$ and mitogen-activated protein kinase (MAPK) pathway have been reported to be associated with the progression of acute lung injury (ALI). Oxymatrine (OMT) alone or combined with other drugs can ameliorate paraquat- or oleic acid-induced lung injury. However, the effect of OMT on lipopolysaccharide (LPS)-induced ALI remains unknown. The aim of the present study was to evaluate whether OMT can attenuate LPS-induced ALI through regulation of the ENaC and MAPK pathway using an ALI mouse model. Histological assessment of the lung and inflammatory cell counts in bronchoalveolar lavage fluid (BALF) were performed by H\&E and Wright-Giemsa staining. The lung wet/dry (W/D) weight ratio and the levels of tumor necrosis factor- $\alpha$ (TNF- $\alpha$ ), C-reactive protein (CRP), ENaC subunits, and the MAPK pathway members were determined. Isolated type II rat alveolar epithelial cells were incubated with OMT $30 \mathrm{~min}$ before LPS stimulation to investigate the activation of ENaC and the MAPK pathway. The results showed that OMT remarkably alleviated histopathologic changes in lung and pulmonary edema, reduced inflammatory cell counts in BALF, and decreased TNF- $\alpha$ and CRP levels in a dose-dependent manner. OMT significantly increased the three subunits of $\mathrm{ENaC}$ proteins in vivo and in vitro, while it decreased $\mathrm{p}$-ERK/ERK, p-p38/p38, and p-JNK/JNK ratios in vivo. However, only the JNK pathway was markedly inhibited in vitro following pretreatment with OMT. Collectively, the results suggested that OMT might alleviate LPS-induced ALI by elevating ENaC proteins and inhibiting the JNK signaling pathway.
\end{abstract}

Key words: acute lung injury, epithelial sodium channel, MAPK, oxymatrine

\section{Introduction}

Acute lung injury (ALI) and its most severe form, acute respiratory distress syndrome (ARDS), are clinically severe respiratory disorders characterized by gas exchange impairment, hemorrhage, and pulmonary edema [38]. LPS is a major component of the outer membrane of Gram-negative bacteria, including Pseudomo- nas aeruginosa (P. aeruginosa). LPS stimulation can activate a variety of immune cells and induce the release of pro-inflammatory and immunoregulatory cytokines from the host, thereby affecting the immune function of the body [44]. When delivered into animals and humans, LPS can cause typical symptoms of lung infection, including pulmonary leukocyte accumulation, edema, severe inflammation, and mortality [29]. 
Oxymatrine (OMT), a quinolizidine alkaloid, is a bioactive ingredient of the traditional Chinese herb Sophorae flavescentis radix (the dried roots of Sophora flavescens Ait) [27]. OMT has been demonstrated to possess antiviral, anticancer, anti-inflammatory, and anti-fibrotic activities [11]. Studies revealed that OMT can alleviate LPS-induced mastitis and acute intestinal inflammation through regulation of the nuclear factor- $\kappa \mathrm{B}(\mathrm{NF}-\kappa \mathrm{B})$ signaling pathway $[13,35]$. A recent study demonstrated that the combination of OMT and sodium ferulate protects mice against ALI. However, the possible mechanism of OMT in LPS-induced ALI remains unclear.

The mitogen-activated protein kinase (MAPK) pathway participates in the release of inflammatory cytokines/mediators in the pathogenesis of inflammatory diseases, including ALI $[3,5]$. A recent study reported that OMT can suppress inflammation responses in LPSactivated microglia through the MAPK pathway [9]. The MAPK pathway is also inactivated in the protection of OMT against sepsis-induced myocardial injury and intracerebral hemorrhage (ICH) $[18,37]$. Xu et al. demonstrated that OMT can attenuate oleic acid-induced ALI by inhibiting the p38 MAPK pathway [34]. The above evidence suggests that the MAPK pathway may be involved in protection of OMT against LPS-induced ALI.

Pulmonary edema is a primary pathological feature of ALI/ARDS, and the epithelial sodium channel $(\mathrm{ENaC})$ plays an important role in relieving pulmonary edema in ALI/ARDS $[8,14]$. In lung tissue, ENaC could transport excess edematous fluid out of the alveolar cavity through the channel transport mechanism [10, 43], whereas abnormally low expression of $\mathrm{ENaC}$ leads to impaired fluid clearance [30]. Dagenais and colleagues demonstrated that $P$. aeruginosa and its secreted LPS reduce the expression and activity of $\mathrm{ENaC}$ in alveolar epithelial cells in vivo and in vitro $[1,6,7,28]$. Moreover, inhibition of the MAPK pathway abrogated LPS-induced $\mathrm{ENaC}$ downregulation [28]. Thus, we speculate that OMT may prevent the downregulation of $\mathrm{ENaC}$ and protect against LPS-induced ALI through regulation of the MAPK pathway.

In the present study, an animal model of ALI was generated in C57BL/6 mice by intratracheal injection of LPS from $P$. aeruginosa. We evaluated the effect of OMT on pathological changes, inflammation in BALF and lung tissues, and pulmonary edema in vivo and clarified the possible mechanisms both in vivo and in vitro.

\section{Materials and Methods}

\section{Ethics statement}

Experimental procedures were approved by the Animal Care and Use Committee of China Medical University and performed in accordance with relevant guidelines (approval number: 2015PS361K).

\section{Animals and groups}

Male C57BL/6 mice (age, 8-10 weeks; weight, 18-22 g) were purchased from Charles River (Beijing, China) and randomly divided into 5 groups (the control group, LPS group, LPS $+12.5 \mathrm{mg} / \mathrm{kg}$ OMT group, LPS +25 $\mathrm{mg} / \mathrm{kg}$ OMT group, and LPS $+50 \mathrm{mg} / \mathrm{kg}$ OMT group) (18 mice/group). After anesthetization, the mice in the LPS group were intratracheally administered $50 \mu \mathrm{g}$ LPS from $P$. aeruginosa serotype 10 (product no.: L9143) (Sigma-Aldrich Corp., St. Louis, MO, USA) in $70 \mu 1$ PBS to establish the ALI model. The mice in the control group received the same volume of PBS in the same way as described above. The mice in the LPS + OMT groups were intraperitoneally injected with $12.5,25$, or $50 \mathrm{mg}$ / kg OMT (Meilunbio, Dalian, China) 30 min before LPS administration. Meanwhile, the mice in the control group and the LPS group were pretreated with an equal volume of sterile saline.

\section{Bronchoalveolar lavage fluid (BALF) cell count}

Six hours after LPS administration, the mice were anesthetized. The trachea was cannulated and lavaged three times with $1.5 \mathrm{ml}$ normal saline $(0.5 \mathrm{ml}$ normal saline each time). BALF was centrifuged at 2,000 rpm for $10 \mathrm{~min}$, and the pellet was resuspended in $0.5 \mathrm{ml}$ PBS. Inflammatory cells (white blood cells, macrophages, neutrophils, and lymphocytes) in $10 \mu 1$ cell suspensions were fixed in methanol and then stained with Wright-Giemsa stain (Nanjing Jiancheng Bioengineering Institute, Nanjing, China). The inflammatory cells were counted under a microscope (Olympus, Tokyo, Japan).

\section{$H \& E$ staining}

At $6 \mathrm{~h}$ post-LPS exposure, the lung tissues were excised, fixed with $4 \%$ paraformaldehyde, dehydrated, and embedded in paraffin. The tissues were cut into $5 \mu \mathrm{m}$ thick sections. After deparaffinization and rehydration, the sections were stained with hematoxylin and eosin. The pathological changes were photographed under a microscope (Olympus). 


\section{ELISA}

The levels of C-reactive protein (CRP) in lung tissues were determined by ELISA kits purchased from USCN Business Co., Ltd. (Wuhan, China), according to the manufacturer's instructions. The tumor necrosis factor (TNF)- $\alpha$ level in the supernatant of tissue homogenate was measured with a Mouse TNF- $\alpha$ ELISA Kit (Boster, Wuhan, China). The optical density at $450 \mathrm{~nm}$ was read on a BioTek microplate reader (BioTek, Winooski, VT, USA).

\section{Lung wet/dry (W/D) weight ratio}

Pulmonary edema was evaluated by measuring the lung wet/dry (W/D) weight ratio. The lung tissues were removed and weighed. Subsequently, they were placed in an incubator for $72 \mathrm{~h}$ to obtain their dry weight. The lung W/D weight ratio was calculated.

\section{Isolation and identification of type II rat alveolar epithelial cells}

Lungs from male Sprague-Dawley rats were washed twice with PBS and were filled with elastase $(4.2 \mathrm{U} / \mathrm{ml})$ via the trachea. After digestion at $37^{\circ} \mathrm{C}$ for $15 \mathrm{~min}$, lung tissues were minced, and elastase was neutralized with $0.25 \%$ DNase I and FBS in a shaker for $10 \mathrm{~min}$. The minced tissues were filtered through filters, and the resultant cell suspension was centrifuged at $1,000 \mathrm{rpm}$ for $10 \mathrm{~min}$ at $4^{\circ} \mathrm{C}$. After discarding the supernatant, the pellet was resuspended in DMEM and purified by the differential adhesion method to remove fibroblasts. Immunofluorescence was performed to identify type II alveolar epithelial cells by using an antibody against surfactant protein-C (SP-C). The cells were mounted on slides, fixed in $4 \%$ paraformaldehyde for $15 \mathrm{~min}$, immersed in $0.1 \%$ Triton X-100 for $30 \mathrm{~min}$, and treated with goat serum for $15 \mathrm{~min}$ at room temperature. Subsequently, the slides were incubated with anti-SP-C antibody (Santa Cruz Biotechnology, Dallas, Texas, USA ; 1:50 dilution) at $4{ }^{\circ} \mathrm{C}$ overnight followed by $60 \mathrm{~min}$ of incubation with $\mathrm{Cy} 3$-conjugated goat anti-rabbit antibody (Beyotime Institute of Biotechnology, Haimen, China; 1:400 dilution) at room temperature. The nuclei were counterstained with DAPI, and the slides were photographed under a fluorescence microscope (Olympus).

\section{Cell culture and treatment}

Type II rat alveolar epithelial cells were cultured in DMEM containing $10 \% \mathrm{FBS}$ in a $5 \% \mathrm{CO}_{2}$ incubator.
The cells were divided into 8 groups (the control group, $250 \mu \mathrm{g} / \mathrm{ml}$ OMT group, $500 \mu \mathrm{g} / \mathrm{ml}$ OMT group, 1,000 $\mu \mathrm{g} / \mathrm{ml}$ OMT group, LPS group, LPS $+250 \mu \mathrm{g} / \mathrm{ml}$ OMT group, LPS $+500 \mu \mathrm{g} / \mathrm{ml}$ OMT group, and LPS $+1,000$ $\mu \mathrm{g} / \mathrm{ml}$ OMT group). The cells in the corresponding groups were pretreated with 250,500 , and $1,000 \mu \mathrm{g} / \mathrm{ml}$ OMT (Meilunbio), respectively. The cells cultured with vehicle were used as the controls. After pretreatment for $30 \mathrm{~min}$, the cells in the corresponding groups were incubated with $15 \mu \mathrm{g} / \mathrm{ml}$ LPS (Sigma-Aldrich Corp.) at $37^{\circ} \mathrm{C}$ until they were subjected to analyses.

\section{MTT assay}

Cell viability was measured by MTT assay at 6,12 , and $24 \mathrm{~h}$. After treatment with OMT and/or LPS, the cells were treated with $5 \mathrm{mg} / \mathrm{ml} \mathrm{MTT} \mathrm{(Sigma-Aldrich}$ Corp.) at $37^{\circ} \mathrm{C}$ for $4 \mathrm{~h}$. The supernatant was discarded. The optical density was determined at $490 \mathrm{~nm}$ after dissolving the crystal violet with $150 \mu 1$ DMSO (SigmaAldrich Corp.).

\section{Real-time PCR}

Total RNAs were obtained from lung tissues or type II alveolar epithelial cells by using RL lysis buffer and then subjected to reverse transcription. Real-time PCR was performed on Bioneer Quantitative Thermal Block (Bioneer, Daejeon, Republic of Korea) with the following amplification conditions: $95^{\circ} \mathrm{C}$ for $10 \mathrm{~min}$ followed by 40 cycles of $95^{\circ} \mathrm{C}$ for $10 \mathrm{~s}, 60^{\circ} \mathrm{C}$ for $20 \mathrm{~s}$, and $72^{\circ} \mathrm{C}$ for $30 \mathrm{~s}$. All the obtained results were normalized to $\beta$-actin, and the relative expression levels of $\alpha-E N a C$, $\beta-E N a C$, and $\gamma-E N a C$ were calculated using the $2^{-\Delta \Delta \mathrm{Ct}}$ formula [25]. The primer sequences were as follows: 5'-ATCACGGAACAGACGCTTT-3', forward, and 5'-CACTTGGGGATTGTTGTCGC-3', reverse, for Mus- $\alpha-E N a C$; 5 '-CAGAAAGGGAGACCCAAAGAGA-3', forward, and 5'-CACTGCCTGGCTTAGCGTCT-3', reverse, for Rat- $\alpha-E N a C$; 5'-CACACACCCCTGGTCCTTA-3', forward, and 5'-CCGCAAGGTACACACAGTT-3', reverse, for Mus$\beta$-ENaC; 5'-AGTGGGGCGTCTTCATCC-3', forward, and 5'-TGGTGGTGTTGGTGTGGCT-3', reverse, for Rat- $\beta$-ENaC; 5'-TACTGCCTGAACACCAACA-3', forward, and 5'-TGATGGAGACAGAGACGGTG-3', reverse, for Mus- $\gamma-E N a C$; 5'-TCACAAACATCTACAACGCTGC-3', forward, and 5'-GGGGTGTTGCTGGTAGTTGC-3', reverse, for Rat- $\gamma-E N a C$; 5'-CTGTGCCCATCTACGAGGGCTAT-3', forward, and 

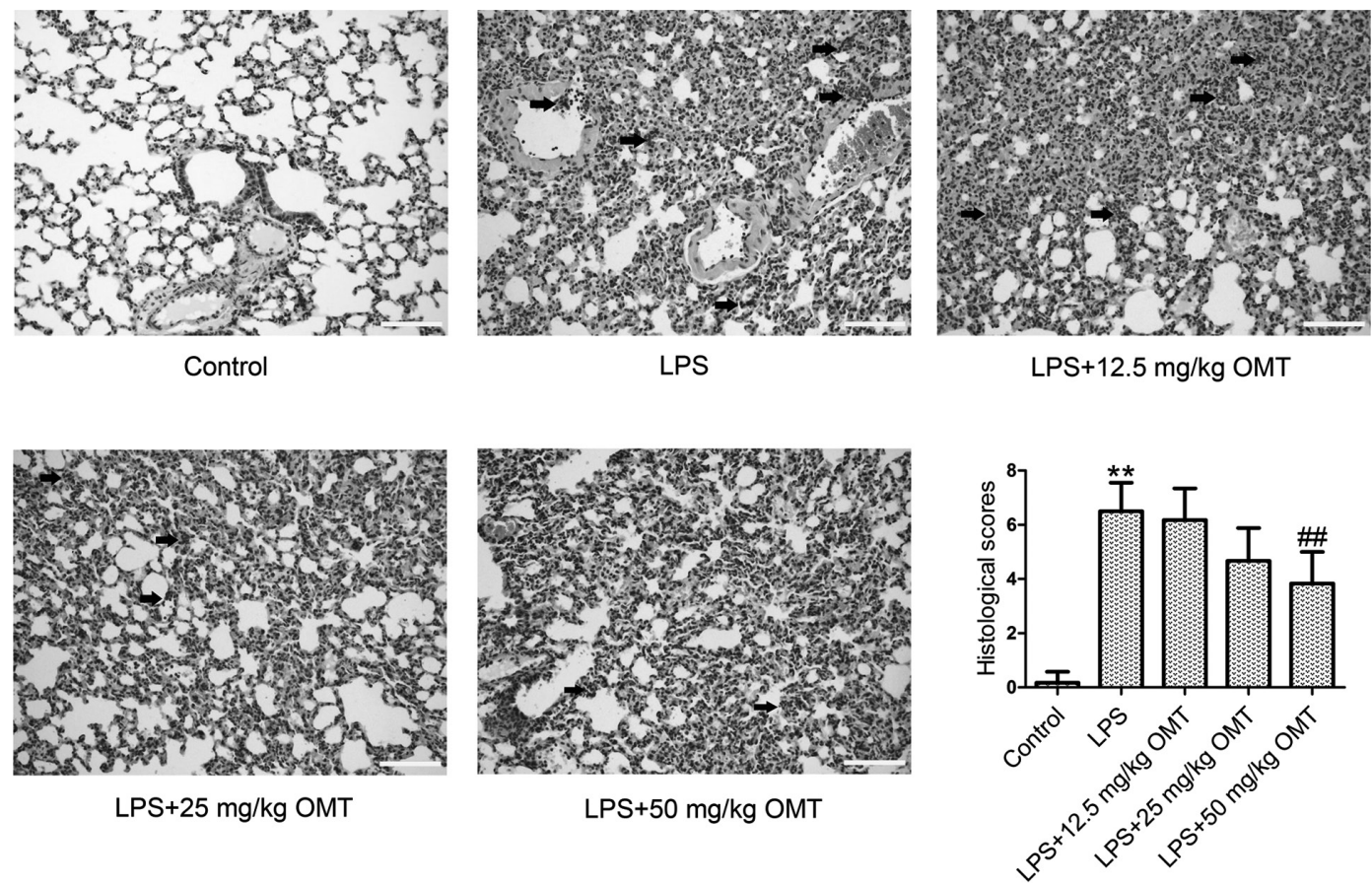

Fig. 1. Pulmonary morphology. The mice (18 mice/group) were pretreated with $12.5,25$, and $50 \mathrm{mg} / \mathrm{kg}$ oxymatrine (OMT) via intraperitoneal injection and then subjected to lipopolysaccharide (LPS; $50 \mu \mathrm{g}$ ) stimulation. Following $6 \mathrm{~h}$ of LPS exposure, lung tissues of the anaesthetized mice were excised, and the tissue sections were examined by H\&E staining. Arrows indicate inflammatory cell clusters (original magnification $\times 200$, scale bars $100 \mu \mathrm{m}$ ). Lung injury score was evaluated by a 9-score system. Data are expressed as the mean \pm SD. Results were analyzed by one-way ANOVA followed by Bonferroni post hoc test. ${ }^{*} P<0.01$ compared with the control group. ${ }^{\#} P<0.01$ compared with the LPS group.

5'-TTTGATGTCACGCACGATTTCC-3', reverse, for Mus- $\beta$-actin; 5'-GGAGATTACTGCCCTGGCTCCTAGC-3', forward, and 5'-GGCCGGACTCATCGTACTCCTGCTT-3', reverse, for Rat- $\beta$-actin.

\section{Western blot}

The cells were trypsinized, harvested, and lysed, and they were then subjected to protein extraction. The obtained total proteins were electrophoresed on SDS-PAGE gels and subsequently transferred onto PVDF membranes (Millipore, Bedford, MA, USA). Skim milk powder was diluted in TTBS solution. After that, the membranes were blocked with diluted milk and incubated with primary antibodies against $\alpha$-ENaC (Proteintech Group, Wuhan, China; 1:500 dilution), $\beta$-ENaC (Proteintech Group; 1:500 dilution), $\gamma$-ENaC (Proteintech Group; 1:1,000 dilution), ERK (Proteintech Group; 1:500 dilution), pERK (BIOSS, Beijing, China; 1:400 dilution), p38 (BIOSS; 1:400 dilution), p-p38 (BIOSS; 1:400 dilution), JNK (Proteintech Group; 1:1,000 dilution) and p-JNK (Abcam, Cambridge Science Park, Cambridge, UK ;
1:1,000 dilution) at $4{ }^{\circ} \mathrm{C}$ overnight. HRP-conjugated secondary antibody (Beyotime Institute of Biotechnology; 1:5,000 dilution) was added after washing with TTBS. Bands were subsequently visualized using ECL reagent (Beyotime Institute of Biotechnology). The optical densities of bands were analyzed by Gel-Pro Analyzer (Media Cybernetics, Inc., Bethesda, MD, USA).

\section{Statistical analysis}

Data are expressed as the mean $\pm \mathrm{SD}$. Results were analyzed by one-way ANOVA followed by Bonferroni post hoc test. A $P$ value $<0.05$ was considered statistically significant.

\section{Results}

OMT attenuates histopathological changes in lung tissues

We evaluated histopathological changes in mice by H\&E staining and assessed lung injury with a 9-score system. As shown in Fig. 1, the mice in the control group showed a normal structure of lung tissues and no histo- 


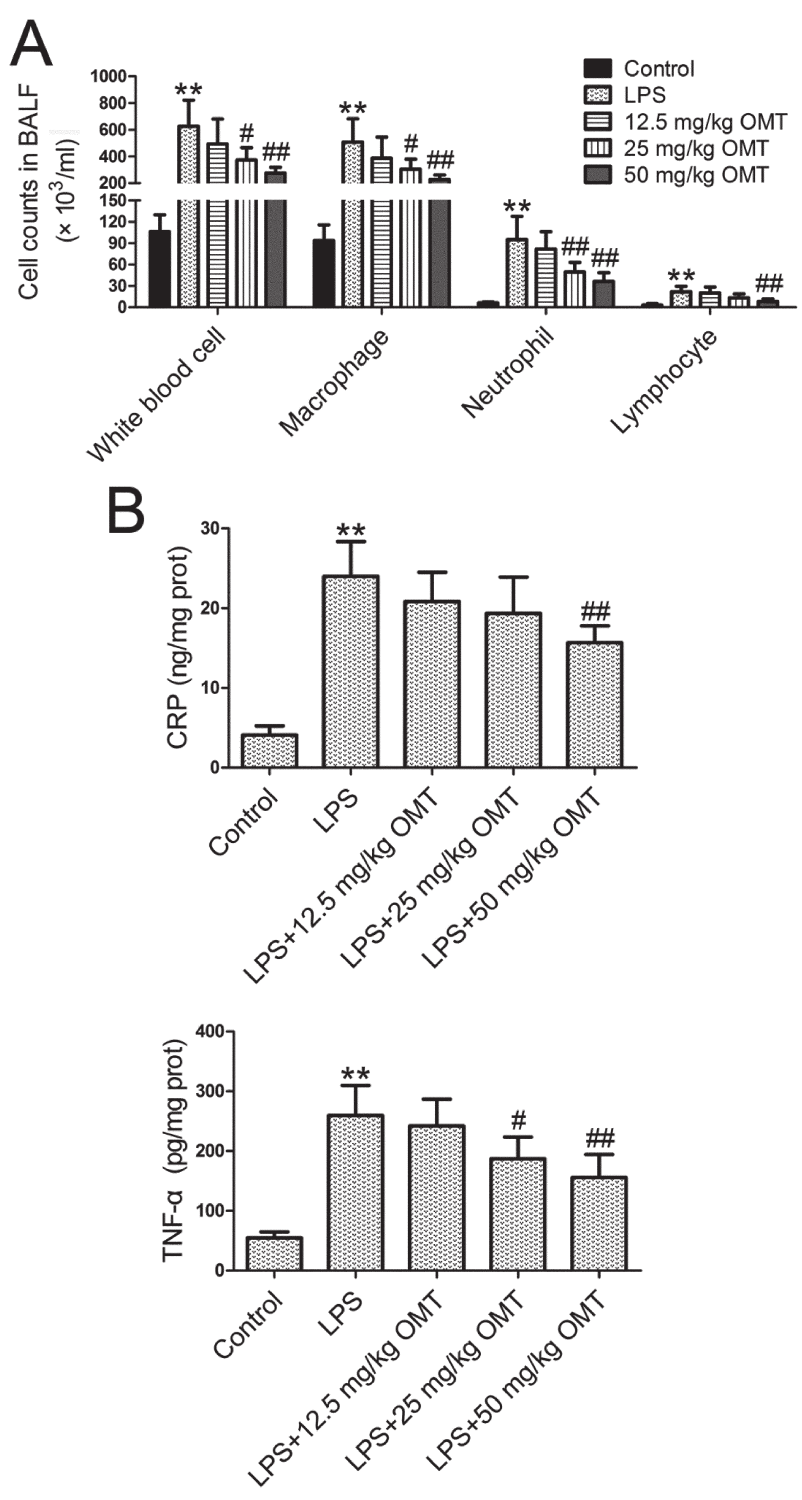

Fig. 2. Inflammation in bronchoalveolar lavage fluid (BALF) and lung tissues. At $6 \mathrm{~h}$ post-LPS exposure, BALF and lung tissues were obtained. A. Inflammatory cell counts in BALF were measured by Wright-Giemsa staining. B. The lung tissue homogenate was centrifuged at $12,000 \mathrm{rpm}$ for $10 \mathrm{~min}$, and the supernatant was harvested. Tumor necrosis factor (TNF)- $\alpha$ and C-reactive protein (CRP) levels were determined using ELISA kits. Data are expressed as the mean $\pm \mathrm{SD}$. Results were analyzed by one-way ANOVA followed by Bonferroni post hoc test. ${ }^{* *} P<0.01$ compared with the control group. ${ }^{\#} P<0.05$ compared with the LPS group. ${ }^{\# \#} P<0.01$ compared with the LPS group.

pathological changes. There were obvious histopathological changes in the lung tissues of the mice in the LPS group, including obvious inflammatory cell infiltration, thickened alveolar walls, severe hemorrhage in the alveolus, and alveolus collapse. After treatment with dif-

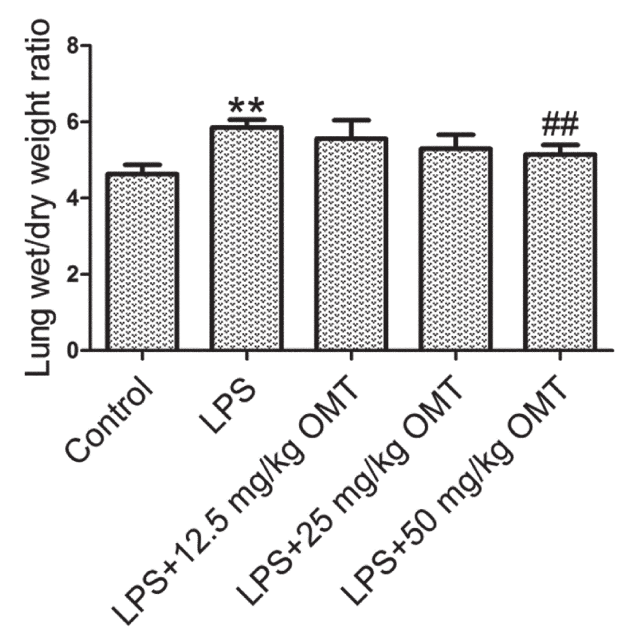

Fig. 3. Pulmonary edema. Lung wet/dry (W/D) weight ratio was measured to evaluate the severity of pulmonary edema. Data are expressed as the mean $\pm \mathrm{SD}$. Results were analyzed by one-way ANOVA followed by Bonferroni posthoc test. $* * P<0.01$ compared with the control group. ${ }^{\# \#} P<0.01$ compared with the LPS group.

ferent doses of OMT, the histopathological changes of the lung were significantly ameliorated in a dose-dependent manner when compared with the LPS group.

OMT attenuates inflammation in ALI induced by LPS in mice

The severity of inflammation was measured by inflammatory cell (white blood cells, macrophages, neutrophils, and lymphocytes) counts in BALF and TNF- $\alpha$ and CRP levels in lung tissues. LPS stimulation significantly increased inflammatory cell counts in BALF (Fig. 2A) and the levels of TNF- $\alpha$ and CRP (Fig. 2B) compared with the control group. Compared with the LPS group, OMT markedly reduced inflammatory cell counts and lung TNF- $\alpha$ and CRP levels in a dose-dependent manner.

\section{OMT attenuates pulmonary edema in mice}

Pulmonary edema can be assessed by lung W/D weight ratio. The results showed that the lung W/D weight ratio was dramatically increased in the LPS group compared with the control group (Fig. 3). OMT lowered the lung W/D weight ratio in a dose-dependent manner compared with the LPS group.

OMT activates the epithelial $\mathrm{Na}^{+}$channel (ENaC) in mice

Real-time PCR and Western blotting results showed that the levels of expression of $\alpha$-ENaC, $\beta$-ENaC, and 

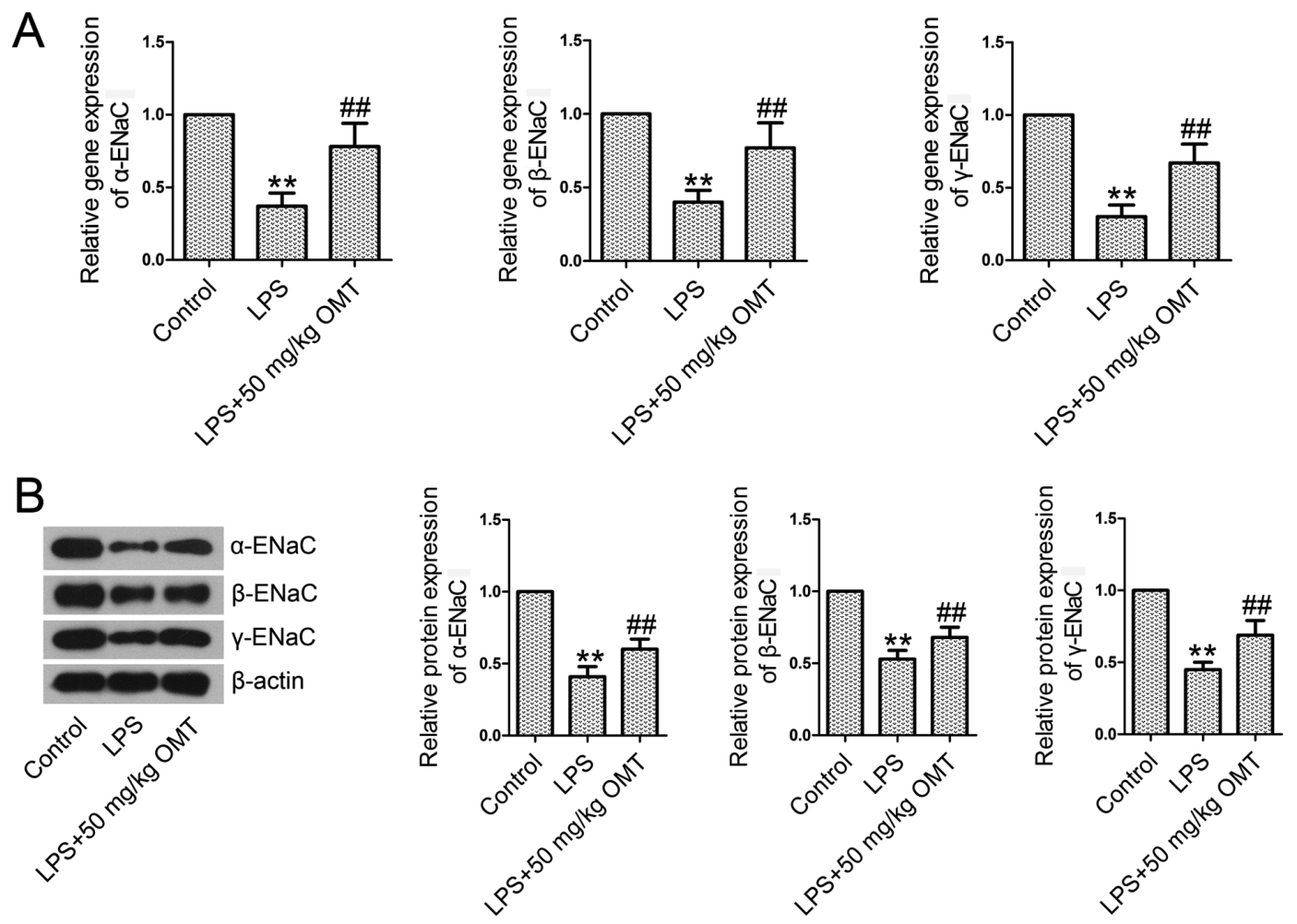

Fig. 4. Epithelial sodium channel $(\mathrm{ENaC})$ subunits in lung tissues. At $6 \mathrm{~h}$ post-LPS exposure, lung tissues were excised. Total RNAs and proteins extracted from the lung tissues were subjected to real-time PCR and Western blotting. A. The mRNA levels of $\alpha-E N a C, \beta-E N a C$, and $\gamma-E N a C$ were examined by real-time PCR analysis. B. The protein levels of $\alpha-\mathrm{ENaC}, \beta-\mathrm{ENaC}$, and $\gamma-\mathrm{ENaC}$ were examined by Western blotting analysis. Data are expressed as the mean $\pm \mathrm{SD}$. Results were analyzed by one-way ANOVA followed by Bonferroni post hoc test. ${ }^{* *} P<0.01$ compared with the control group. ${ }^{\#} P<0.01$ compared with the LPS group.

$\gamma$-ENaC at mRNA (Fig. 4A) and protein (Fig. 4B) levels were significantly lower in the LPS group than those in the control group. However, OMT administration obviously upregulated the reduced levels of $\alpha-\mathrm{ENaC}$, $\beta-\mathrm{ENaC}$, and $\gamma-\mathrm{ENaC}$, indicating the activation of $\mathrm{ENaC}$.

OMT inhibits the activation of the mitogen-activated protein kinase (MAPK) pathway in mice

Extracellular signal-regulated kinase (ERK), c-Jun $\mathrm{N}$-terminal kinase (JNK), and $\mathrm{p} 38$ are members of the MAPK pathway. To examine the involvement of the MAPK pathway, we measured the levels of MAPK pathway members. We found that the expression levels of phosphorylated forms of ERK, p38, and JNK were notably increased in the LPS group compared with the control group (Fig. 5). However, OMT treatment resulted in remarkable decreases in p-ERK, p-p38, and p-JNK expression compared with the LPS group.
Identification of type II alveolar epithelial cells and cytotoxicity of OMT

In our in vitro study, we firstly identified the isolated cells using immunofluorescence staining for SP-C. As shown in Fig. 6A, the results showed that type II rat alveolar epithelial cells were successfully isolated. Then, we examined the cytotoxicity of OMT in type II rat alveolar epithelial cells by MTT assay. The results showed that $\operatorname{OMT}(250,500$, and $1,000 \mu \mathrm{g} / \mathrm{ml})$ had no cytotoxicity in type II rat alveolar epithelial cells (Fig. 6B). The addition of LPS significantly reduced the cell viability of type II alveolar epithelial cells. OMT preconditioning, especially at the dose of $500 \mu \mathrm{g} / \mathrm{ml}$, slightly abolished the effect of LPS at $24 \mathrm{~h}$.

\section{OMT activates ENaC in alveolar epithelial cells}

We further confirmed whether $\mathrm{ENaC}$ was activated in type II alveolar epithelial cells using real-time PCR and Western blotting. In the LPS group, the mRNA (Fig. 7A) and protein (Fig. 7B) levels of $\alpha$-ENaC, $\beta$-ENaC, and 

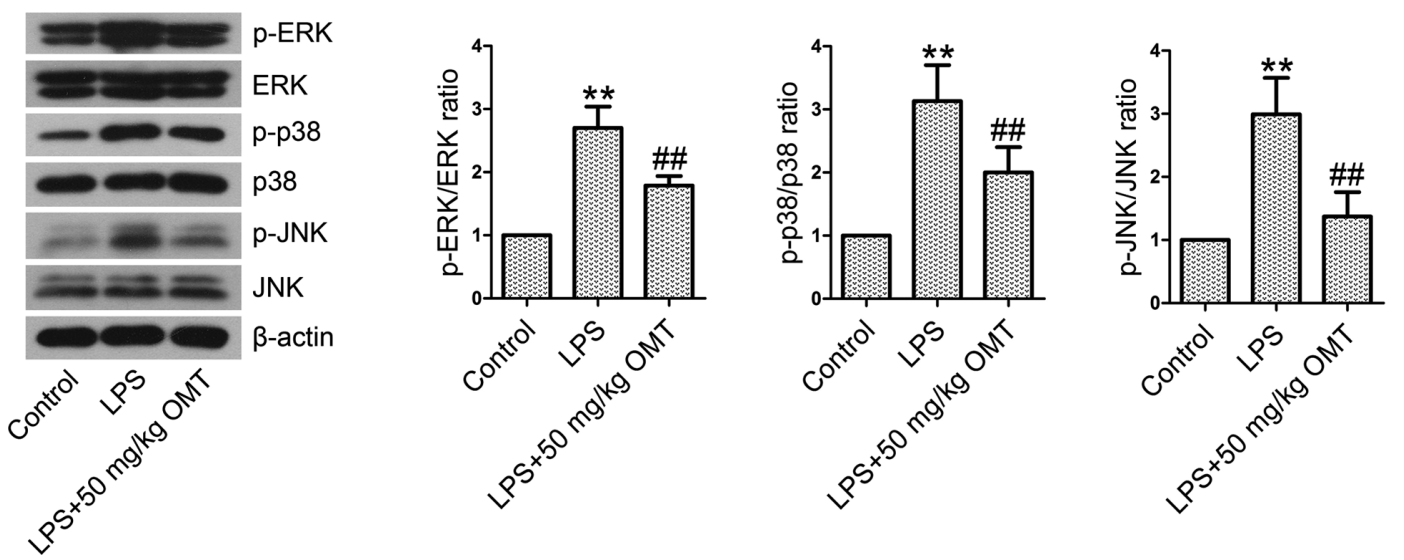

Fig. 5. The activation of the MAPK signaling pathway in lung tissues. The expression levels of p-ERK, ERK, p-p38, p38, p-JNK, and JNK were quantified by Western blotting analysis. The ratios of p-ERK/ERK, p-p38/p38, and p-JNK/ JNK were calculated. Data are expressed as the mean \pm SD. Results were analyzed by one-way ANOVA followed by Bonferroni post hoc test. ${ }^{* *} P<0.01$ compared with the control group. ${ }^{\#} P<0.01$ compared with the LPS group.
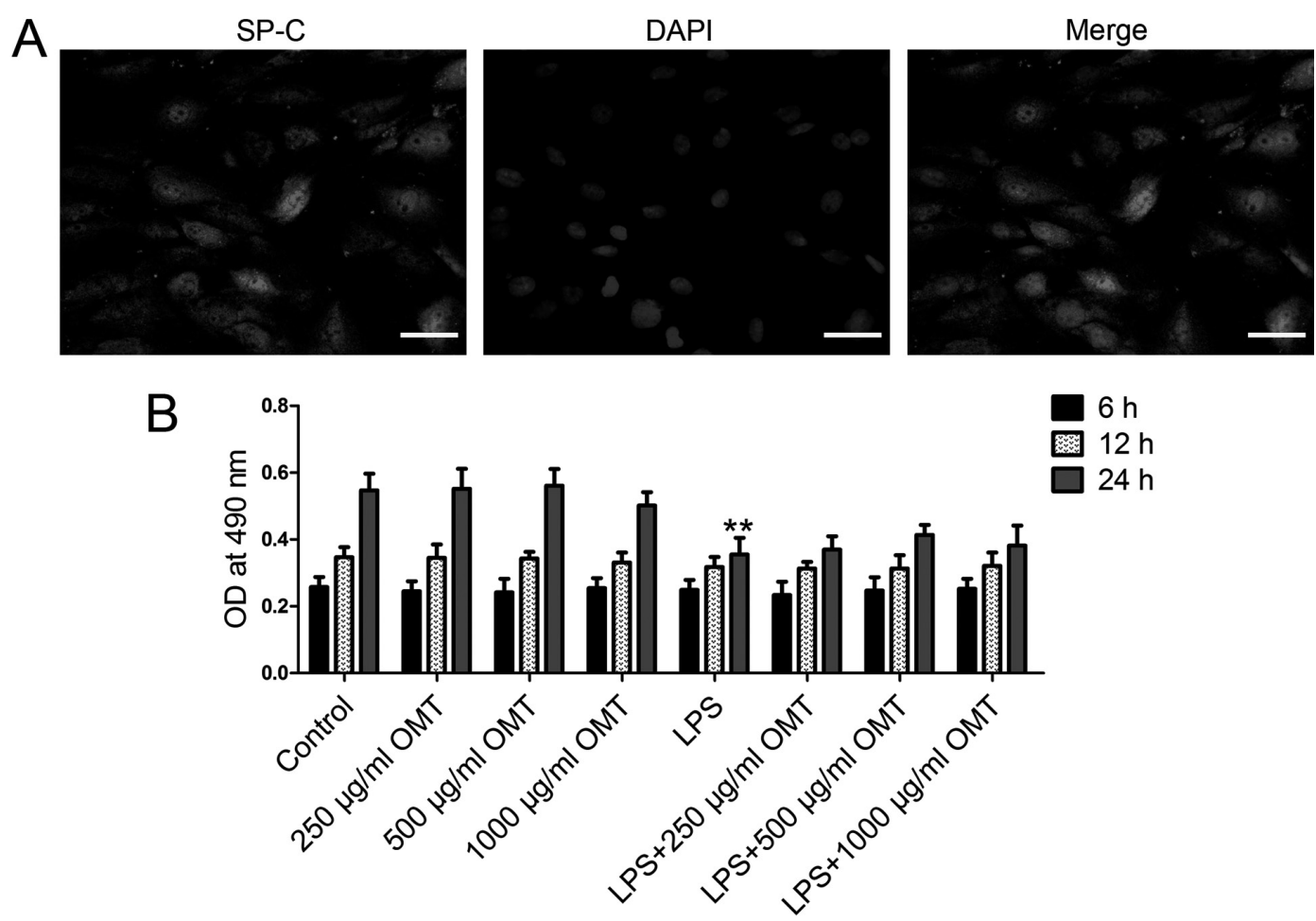

Fig. 6. Identification of type II alveolar epithelial cells and cytotoxicity of OMT. A. The isolated cells were identified by immunofluorescence using anti-SP-C antibody. B. Rat type II alveolar epithelial cells were pretreated with different doses of OMT $(250,500$, and $1,000 \mu \mathrm{g} / \mathrm{ml} \mathrm{OMT})$, and then LPS $(15 \mu \mathrm{g} / \mathrm{ml})$ was added 30 min post-OMT addition. After 6,12 , and $24 \mathrm{~h}$, cytotoxicity of OMT was examined by MTT assay. The optical density was determined at $490 \mathrm{~nm}$. Data are expressed as the mean $\pm \mathrm{SD}$. Results were analyzed by one-way ANOVA followed by Bonferroni post hoc test. $* * P<0.01$ compared with the control group.

$\gamma$-ENaC were decreased compared with the control group. However, OMT injection restored the levels of $\alpha$-ENaC, $\beta$-ENaC, and $\gamma$-ENaC.
OMT inhibits the activation of the JNK pathway in type II alveolar epithelial cells

The expression levels of MAPK pathway members and their phosphorylated forms in type II alveolar epi- 

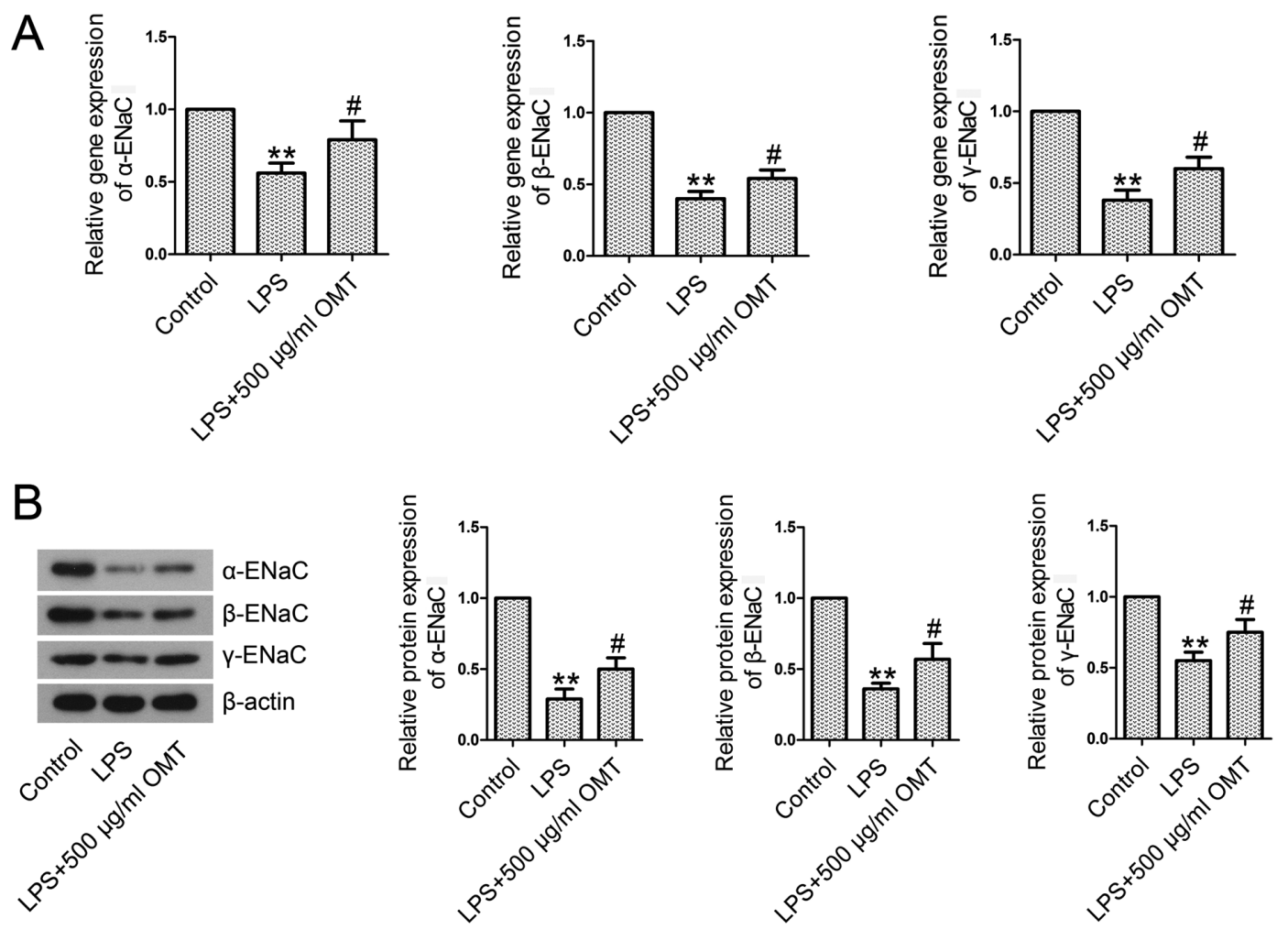

Fig. 7. ENaC subunits in rat type II alveolar epithelial cells. The cells were treated with $500 \mu \mathrm{g} / \mathrm{ml} \mathrm{OMT} ; 30 \mathrm{~min}$ later, the cells were exposed to LPS $(15 \mu \mathrm{g} / \mathrm{ml})$ for $6 \mathrm{~h}$. A. Real-time PCR analysis of $\alpha-E N a C, \beta-E N a C$, and $\gamma-E N a C$. B. Western blotting analysis of $\alpha-\mathrm{ENaC}, \beta-\mathrm{ENaC}$, and $\gamma$-ENaC. Data are expressed as the mean \pm SD. Results were analyzed by one-way ANOVA followed by Bonferroni post hoc test. $* * P<0.01$ compared with the control group. ${ }^{\#} P<0.05$ compared with the LPS group.

thelial cells were examined by Western blotting. As shown in Fig. 8, the protein levels of p-ERK, p-p38, and p-JNK were shown to be elevated by LPS exposure. OMT preconditioning significantly reduced the ratios of p-JNK/JNK in LPS-stimulated cells. The differences were not statistically significant, although p-ERK/ERK and p-p38/p38 ratios were decreased by OMT preconditioning.

\section{Discussion}

LPS is the pathogenic constituent of $P$. aeruginosa and can induce strong immune responses in bodies [2]. LPS has been widely used to establish the experimental model of ALI [32, 42]. Our present study investigated the protective effect of oxymatrine (OMT) preconditioning on acute lung injury (ALI) and further elucidated the possible mechanisms.

$\mathrm{Xu}$ et al. demonstrated that OMT attenuates oleic acid-induced ALI by inhibiting pulmonary edema and inflammatory cell infiltration in alveolar spaces [34]. Yuan et al. found that sodium ferulate combined with OMT decreases inflammatory cells in BALF and alleviates pulmonary edema in a LPS-induced ALI mouse model [36]. Additionally, OMT has been applied in the treatment of acute pancreatitis and acute intestinal inflammation due to its anti-inflammatory effect $[13,41]$. In our study, Wright-Giemsa staining results consistently showed that OMT dose-dependently decreased LPS-induced increases of inflammatory cell (white blood cells, macrophages, neutrophils, and lymphocyte) numbers in BALF. C-reactive protein (CRP) is an important indicator of inflammation and correlates with the severity of diseases, which is markedly increased after bacterial infection [21]. TNF- $\alpha$ is a vital pro-inflammatory cytokine that can activate other cytokines and chemokines to aggravate lung tissue injury. Zhang et al. found that OMT pretreatment inhibits the expression of TNF- $\alpha$ and IL-1 $\beta$ in LPS-stimulated macrophages [40]. Moreover, we found that OMT significantly reduced the up- 

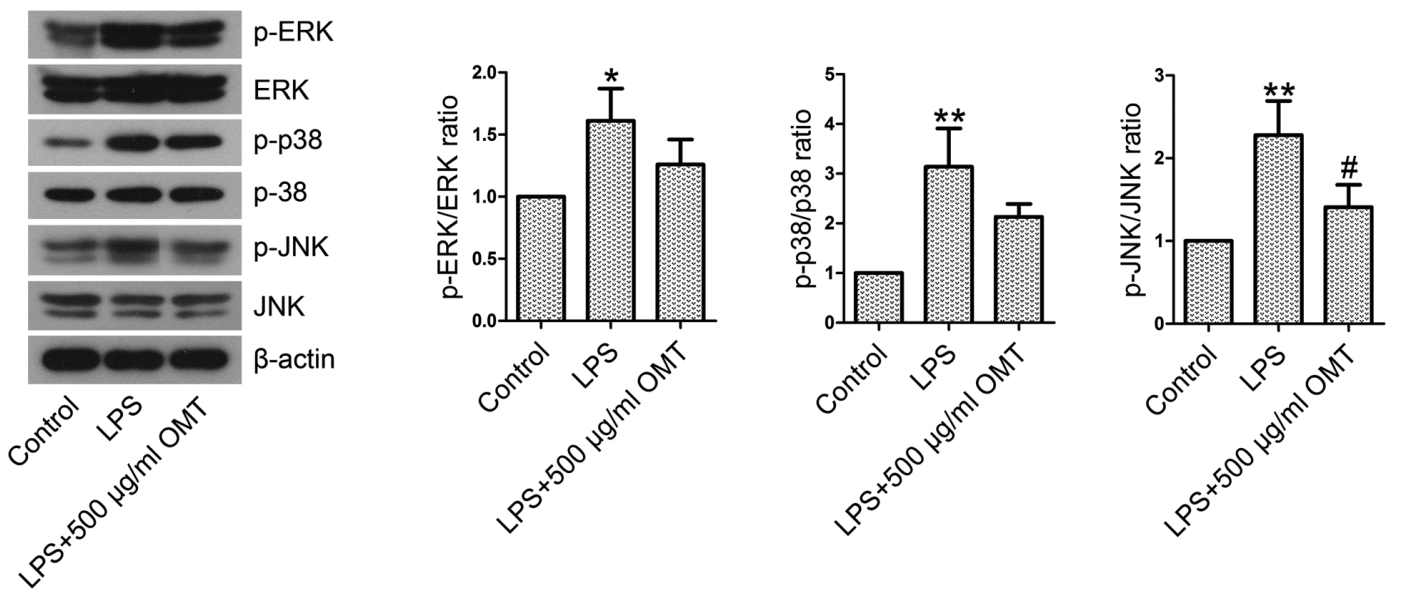

Fig. 8. The activation of the MAPK signaling pathway in rat type II alveolar epithelial cells. Thirty minutes following OMT $(500 \mu \mathrm{g} / \mathrm{ml})$ treatment, the cells were exposed to LPS $(15 \mu \mathrm{g} / \mathrm{ml})$ for $30 \mathrm{~min}$. The expression levels of p-ERK, ERK, p-p38, p38, p-JNK, and JNK were quantified by Western blotting analysis. The ratios of p-ERK/ERK, p-p38/p38, and p-JNK/JNK were calculated. Data are expressed as the mean \pm SD. Results were analyzed by one-way ANOVA followed by Bonferroni post hoc test. $* P<0.05$ compared with the control group. ${ }^{* *} P<0.01$ compared with the control group. ${ }^{\#} P<0.05$ compared with the LPS group.

regulated levels of CRP and TNF- $\alpha$ in lung tissues induced by LPS exposure. The data suggest that OMT administration may protect against LPS-induced ALI via its anti-inflammatory effect.

ALI is characterized by inflammation, pulmonary edema, and alveolar-capillary barrier damage. The lung W/D weight ratio is an index of pulmonary edema [39]. In our study, we found that OMT significantly alleviated histopathological changes and inhibited pulmonary edema induced by LPS.

The epithelial sodium channel $(\mathrm{ENaC})$ consists of three subunits $(\alpha, \beta$, and $\gamma)$ [26]. Alpha-ENaC forms the channel pore, while $\beta$-ENaC and $\gamma$-ENaC are associated with the channel activity $[24,26]$. ENaC plays a major role in sodium and water homeostasis [4]. Knockdown of $\alpha-E N a C$ by siRNA transfection inhibits lung fluid absorption in SD rats [23]. Hummler et al. found that $\alpha-E N a C$-deficient neonatal mice fail to clear lung fluid, develop respiratory distress, and die within $40 \mathrm{~h}$ of birth [19]. Roux et al. reported that IL-1 $\beta$ reduces $\alpha$-ENaC expression and activity, inhibits lung epithelial sodium absorption, and ultimately contributes to alveolar edema via the p38 MAPK signaling pathway [31]. We found that LPS administration decreased the expression levels of $\alpha-\mathrm{ENaC}, \beta-\mathrm{ENaC}$, and $\gamma$-ENaC in lung tissues and alveolar epithelial cells, whereas OMT treatment increased $\alpha$-ENaC, $\beta$-ENaC, and $\gamma$-ENaC levels. The data suggest that OMT administration may alleviate pulmo- nary edema via ENaC.

MAPKs, including extracellular signal-regulated kinase (ERK), p38 MAPK, and c-Jun N-terminal kinase (JNK), are members of the serine/threonine kinase family, which participate in signal transduction in eukaryotic organisms [22]. MAPKs play important roles in inflammation, oncogenesis, cell proliferation, apoptosis, differentiation, and stress responses [17, 20]. The MAPK signaling pathway is inhibited by OMT administration in LPS-induced mastitis in mice [35]. Moreover, OMT protects rats against myocardial injury in a rat model of sepsis via suppression of the $\mathrm{p} 38$ MAPK signaling pathway [37]. We found that OMT administration significantly inhibited LPS-induced activation of the MAPK signaling pathway in a mouse model of ALI. As expected, we consistently observed suppression of the JNK signaling pathway in OMT-treated alveolar epithelial cells in vitro. LPS-induced activation of the ERK and p38 pathways was slightly inhibited by OMT; however, the difference was not statistically significant. The data suggest that OMT administration may protect against LPS-induced ALI in vivo and in vitro by inhibiting the JNK signaling pathway. Toll-like receptor 4 (TLR4) can recognize and interact with LPS and subsequently activate the downstream MAPK pathways, eventually leading to an inflammatory response $[12,15]$. Previous studies reported that LPS-induced ALI can be attenuated by other drugs through the TLR4-mediated MAPK pathway 
$[16,33]$. OMT may also ameliorate ALI induced by LPS by inhibiting the TLR4-mediated signaling pathways; however, the precise mechanism requires further investigation and verification.

In summary, the results demonstrated that pretreatment with OMT attenuated LPS-induced ALI in both C57BL/6 mice and rat alveolar epithelial cells. The inhibitory effects of OMT on ALI were associated with the $\mathrm{ENaC}$ and JNK signaling pathway.

\section{Conflict of Interest}

The authors declare that they have no competing interests.

\section{References}

1. Boncoeur, E., Tardif, V., Tessier, M.C., Morneau, F., Lavoie, J., Gendreau-Berthiaume, E., Grygorczyk, R., Dagenais, A., and Berthiaume, Y. 2010. Modulation of epithelial sodium channel activity by lipopolysaccharide in alveolar type II cells: involvement of purinergic signaling. Am. J. Physiol. Lung Cell. Mol. Physiol. 298: L417-L426. [Medline] [CrossRef]

2. Buyck, J.M., Verriere, V., Benmahdi, R., Higgins, G., Guery, B., Matran, R., Harvey, B.J., Faure, K., and Urbach, V. 2013. P. aeruginosa LPS stimulates calcium signaling and chloride secretion via CFTR in human bronchial epithelial cells. $J$. Cyst. Fibros. 12: 60-67. [Medline] [CrossRef]

3. Chen, Y., Wang, L., Kang, Q., Zhang, X., Yu, G., Wan, X., Wang, J., and Zhu, K. 2017. Heat Shock Protein A12B Protects Vascular Endothelial Cells Against Sepsis-Induced Acute Lung Injury in Mice. Cell. Physiol. Biochem. 42: 156-168. [Medline] [CrossRef]

4. Chifflet, S. and Hernandez, J.A. 2016. The epithelial sodium channel and the processes of wound healing. BioMed Res. Int. 2016: 5675047. [Medline] [CrossRef]

5. Cornell, T.T., Fleszar, A., McHugh, W., Blatt, N.B., Le Vine, A.M., and Shanley, T.P. 2012. Mitogen-activated protein kinase phosphatase 2, MKP-2, regulates early inflammation in acute lung injury. Am. J. Physiol. Lung Cell. Mol. Physiol. 303: L251-L258. [Medline] [CrossRef]

6. Dagenais, A., Denis, C., Vives, M.F., Girouard, S., Massé, C., Nguyen, T., Yamagata, T., Grygorczyk, C., Kothary, R., and Berthiaume, Y. 2001. Modulation of alpha-ENaC and alpha1-Na+-K+-ATPase by cAMP and dexamethasone in alveolar epithelial cells. Am. J. Physiol. Lung Cell. Mol. Physiol. 281: L217-L230. [Medline] [CrossRef]

7. Dagenais, A., Gosselin, D., Guilbault, C., Radzioch, D., and Berthiaume, Y. 2005. Modulation of epithelial sodium channel (ENaC) expression in mouse lung infected with Pseudomonas aeruginosa. Respir. Res. 6: 2. [Medline] [CrossRef]

8. Deng, W., Li, C.Y., Tong, J., Zhang, W., and Wang, D.X. 2012. Regulation of ENaC-mediated alveolar fluid clearance by insulin via PI3K/Akt pathway in LPS-induced acute lung injury. Respir. Res. 13: 29. [Medline] [CrossRef]

9. Dong, X.Q., Du, Q., Yu, W.H., Zhang, Z.Y., Zhu, Q., Che, Z.H., Chen, F., Wang, H., and Chen, J. 2013. Anti-inflammatory Effects of Oxymatrine Through Inhibition of Nuclear Factor-kappa B and Mitogen-activated Protein Kinase Activation in Lipopolysaccharide-induced BV2 Microglia Cells. Iran. J. Pharm. Res. 12: 165-174. [Medline]

10. Elias, N., Rafii, B., Rahman, M., Otulakowski, G., Cutz, E., and O'Brodovich, H. 2007. The role of alpha-, beta-, and gamma-ENaC subunits in distal lung epithelial fluid absorption induced by pulmonary edema fluid. Am. J. Physiol. Lung Cell. Mol. Physiol. 293: L537-L545. [Medline] [CrossRef]

11. Fu, L., Xu, Y., Tu, L., Huang, H., Zhang, Y., Chen, Y., Tao, L., and Shen, X. 2016. Oxymatrine inhibits aldosterone-induced rat cardiac fibroblast proliferation and differentiation by attenuating smad-2,-3 and-4 expression: an in vitro study. $B M C$ Complement. Altern. Med. 16: 241. [Medline] [CrossRef]

12. Gu, J., Su, S., Guo, J., Zhu, Y., Zhao, M., and Duan, J.A. 2018. Anti-inflammatory and anti-apoptotic effects of the combination of Ligusticum chuanxiong and Radix Paeoniae against focal cerebral ischaemia via TLR4/MyD88/MAPK/ NF-אB signalling pathway in MCAO rats. J. Pharm. Pharmacol. 70: 268-277. [Medline] [CrossRef]

13. Guzman, J.R., Koo, J.S., Goldsmith, J.R., Mühlbauer, M., Narula, A., and Jobin, C. 2013. Oxymatrine prevents NF-kB nuclear translocation and ameliorates acute intestinal inflammation. Sci. Rep. 3: 1629. [Medline] [CrossRef]

14. He, J., Zhao, Y., Deng, W., and Wang, D.X. 2014. Netrin-1 promotes epithelial sodium channel-mediated alveolar fluid clearance via activation of the adenosine $2 \mathrm{~B}$ receptor in lipopolysaccharide-induced acute lung injury. Respiration 87 : 394-407. [Medline] [CrossRef]

15. Hu, G., Hong, D., Zhang, T., Duan, H., Wei, P., Guo, X., and $\mathrm{Mu}, \mathrm{X}$. 2017. Cynatratoside-C from Cynanchum atratum displays anti-inflammatory effect via suppressing TLR4 mediated NF- $\mathrm{kB}$ and MAPK signaling pathways in LPS-induced mastitis in mice. Chem. Biol. Interact. 279: 187-195. [Medline]

16. Hu, Y., Tao, L., Tan, H., Zhang, M., Shimizu, K., Zhang, F., and Zhang, C. 2017. An Active Drimane-Type Lactone from Polygonum jucundum Attenuates LipopolysaccharideInduced Acute Lung Injury in Mice Through TLR4-MAPKs Signaling Pathway. Inflammation 40: 1204-1213. [Medline] [CrossRef]

17. Huang, C., Jacobson, K., and Schaller, M.D. 2004. MAP kinases and cell migration. J. Cell Sci. 117: 4619-4628. [Medline] [CrossRef]

18. Huang, M., Hu, Y.Y., Dong, X.Q., Xu, Q.P., Yu, W.H., and Zhang, Z.Y. 2012. The protective role of oxymatrine on neuronal cell apoptosis in the hemorrhagic rat brain. J. Ethnopharmacol. 143: 228-235. [Medline] [CrossRef]

19. Hummler, E., Barker, P., Gatzy, J., Beermann, F., Verdumo, C., Schmidt, A., Boucher, R., and Rossier, B.C. 1996. Early death due to defective neonatal lung liquid clearance in alpha-ENaC-deficient mice. Nat. Genet. 12: 325-328. [Medline] [CrossRef]

20. Jiang, M., Li, J., Peng, Q., Liu, Y., Liu, W., Luo, C., Peng, J., Li, J., Yung, K.K., and Mo, Z. 2014. Neuroprotective effects 
of bilobalide on cerebral ischemia and reperfusion injury are associated with inhibition of pro-inflammatory mediator production and down-regulation of JNK1/2 and p38 MAPK activation. J. Neuroinflammation 11: 167. [Medline] [CrossRef]

21. Juan, X., Lu, Y.M., Shi, J.D., Deng, X.Q., and Long, W. 2011. Visfatin levels in patients with severe pneumonia. World J. Emerg. Med. 2: 132-136. [Medline] [CrossRef]

22. Li, D., Hu, J., Wang, T., Zhang, X., Liu, L., Wang, H., Wu, Y., Xu, D., and Wen, F. 2016. Silymarin attenuates cigarette smoke extract-induced inflammation via simultaneous inhibition of autophagy and ERK/p38 MAPK pathway in human bronchial epithelial cells. Sci. Rep. 6: 37751. [Medline] [CrossRef]

23. Li, T. and Folkesson, H.G. 2006. RNA interference for alpha-ENaC inhibits rat lung fluid absorption in vivo. Am. J. Physiol. Lung Cell. Mol. Physiol. 290: L649-L660. [Medline] [CrossRef]

24. Liu, Y., Jiang, B.J., Zhao, R.Z., and Ji, H.L. 2016. Epithelial sodium channels in pulmonary epithelial progenitor and stem cells. Int. J. Biol. Sci. 12: 1150-1154. [Medline] [CrossRef]

25. Livak, K.J. and Schmittgen, T.D. 2001. Analysis of relative gene expression data using real-time quantitative PCR and the 2(-Delta Delta C(T)) Method. Methods 25: 402-408. [Medline] [CrossRef]

26. Loh, S.Y., Giribabu, N., and Salleh, N. 2016. Sub-chronic testosterone treatment increases the levels of epithelial sodium channel (ENaC)- $\alpha, \beta$ and $\gamma$ in the kidney of orchidectomized adult male Sprague-Dawley rats. PeerJ 4: e2145. [Medline] [CrossRef]

27. Lu, H., Zhang, L., Gu, L.L., Hou, B.Y., and Du, G.H. 2016. Oxymatrine induces liver injury through JNK signalling pathway mediated by TNF- $\alpha$ in vivo. Basic Clin. Pharmacol. Toxicol. 119: 405-411. [Medline] [CrossRef]

28. Migneault, F., Boncoeur, E., Morneau, F., Pascariu, M., Dagenais, A., and Berthiaume, Y. 2013. Cycloheximide and lipopolysaccharide downregulate $\alpha \mathrm{ENaC}$ mRNA via different mechanisms in alveolar epithelial cells. Am. J. Physiol. Lung Cell. Mol. Physiol. 305: L747-L755. [Medline] [CrossRef]

29. Mirzapoiazova, T., Kolosova, I.A., Moreno, L., Sammani, S., Garcia, J.G., and Verin, A.D. 2007. Suppression of endotoxin-induced inflammation by taxol. Eur. Respir. J. 30: 429-435. [Medline] [CrossRef]

30. Randrianarison, N., Clerici, C., Ferreira, C., Fontayne, A., Pradervand, S., Fowler-Jaeger, N., Hummler, E., Rossier, B.C., and Planès, C. 2008. Low expression of the beta-ENaC subunit impairs lung fluid clearance in the mouse. Am. J. Physiol. Lung Cell. Mol. Physiol. 294: L409-L416. [Medline] [CrossRef]

31. Roux, J., Kawakatsu, H., Gartland, B., Pespeni, M., Sheppard, D., Matthay, M.A., Canessa, C.M., and Pittet, J.F. 2005. Interleukin-1beta decreases expression of the epithelial sodium channel alpha-subunit in alveolar epithelial cells via a p38 MAPK-dependent signaling pathway. J. Biol. Chem. 280: 18579-18589. [Medline] [CrossRef]

32. Wu, G., Wang, J., Luo, P., Li, A., Tian, S., Jiang, H., Zheng, Y., Zhu, F., Lu, Y., and Xia, Z. 2017. Hydrostatin-SN1, a sea snake-derived bioactive peptide, reduces inflammation in a mouse model of acute lung injury. Front. Pharmacol. 8: 246.
[Medline] [CrossRef]

33. Wu, K.C., Huang, S.S., Kuo, Y.H., Ho, Y.L., Yang, C.S., Chang, Y.S., and Huang, G.J. 2017. Ugonin M, a Helminthostachys zeylanica Constituent, Prevents LPS-Induced Acute Lung Injury through TLR4-Mediated MAPK and NFкB Signaling Pathways. Molecules 22: E573. [Medline]

34. Xu, G.L., Yao, L., Rao, S.Y., Gong, Z.N., Zhang, S.Q., and Yu, S.Q. 2005. Attenuation of acute lung injury in mice by oxymatrine is associated with inhibition of phosphorylated p38 mitogen-activated protein kinase. J. Ethnopharmacol. 98: 177-183. [Medline] [CrossRef]

35. Yang, Z., Yin, R., Cong, Y., Yang, Z., Zhou, E., Wei, Z., Liu, Z., Cao, Y., and Zhang, N. 2014. Oxymatrine lightened the inflammatory response of LPS-induced mastitis in mice through affecting NF- $\mathrm{KB}$ and MAPKs signaling pathways. Inflammation 37: 2047-2055. [Medline] [CrossRef]

36. Yuan, X., Wang, Y., Du, D., Hu, Z., Xu, M., Xu, M., and Liu, Z. 2012. The effects of the combination of sodium ferulate and oxymatrine on lipopolysaccharide-induced acute lung injury in mice. Inflammation 35: 1161-1168. [Medline] [CrossRef]

37. Zhang, M., Wang, X., Bai, B., Zhang, R., Li, Y., and Wang, Y. 2016. Oxymatrine protects against sepsis-induced myocardial injury via inhibition of the TNF- $\alpha / \mathrm{p} 38$-MAPK/caspase-3 signaling pathway. Mol. Med. Rep. 14: 551-559. [Medline] [CrossRef]

38. Zhang, Y., Li, X., Grailer, J.J., Wang, N., Wang, M., Yao, J., Zhong, R., Gao, G.F., Ward, P.A., Tan, D.X., and Li, X. 2016. Melatonin alleviates acute lung injury through inhibiting the NLRP3 inflammasome. J. Pineal Res. 60: 405-414. [Medline] [CrossRef]

39. Zhang, Y., Xu, T., Wu, B., Chen, H., Pan, Z., Huang, Y., Mei, L., Dai, Y., Liu, X., Shan, X., and Liang, G. 2017. Targeting myeloid differentiation protein 2 by the new chalcone L2H21 protects LPS-induced acute lung injury. J. Cell. Mol. Med. 21: 746-757. [Medline] [CrossRef]

40. Zhang, Y., Yan, R., and Hu, Y. 2015. Oxymatrine inhibits lipopolysaccharide-induced inflammation by down-regulating Toll-like receptor 4/nuclear factor-kappa B in macrophages. Can. J. Physiol. Pharmacol. 93: 253-260. [Medline] [CrossRef]

41. Zhang, Z., Wang, Y., Dong, M., Cui, J., Rong, D., and Dong, Q. 2012. Oxymatrine ameliorates L-arginine-induced acute pancreatitis in rats. Inflammation 35: 605-613. [Medline] [CrossRef]

42. Zhu, G., Xin, X., Liu, Y., Huang, Y., Li, K., and Wu, C. 2017. Geraniin attenuates LPS-induced acute lung injury via inhibiting NF- $\mathrm{BB}$ and activating Nrf2 signaling pathways. Oncotarget 8: 22835-22841. [Medline]

43. Zhu, T., Zhang, W., and Wang, D.X. 2012. Insulin up-regulates epithelial sodium channel in LPS-induced acute lung injury model in rats by SGK1 activation. Injury 43: 12771283. [Medline] [CrossRef]

44. Zhu, Y., Chen, X., Liu, Z., Peng, Y.P., and Qiu, Y.H. 2015. Interleukin-10 protection against lipopolysaccharide-induced neuro-inflammation and neurotoxicity in ventral mesencephalic cultures. Int. J. Mol. Sci. 17: E25. [Medline] [CrossRef] 